\title{
Dynamic Evolution of Knowledge Sharing Behavior among Enterprises in the Cluster Innovation Network Based on Evolutionary Game Theory
}

\author{
Xiaodan Kong ${ }^{1, *}$, Qi Xu ${ }^{1}$ (i) and Tao Zhu ${ }^{2}$ \\ 1 Glorious Sun School of Business and Management, Donghua University, Shanghai 200051, China; \\ xuqi@dhu.edu.cn \\ 2 Faculty of Engineering and Physical Sciences, University of Southampton, Southampton SO171TU, UK; \\ t.zhu@soton.ac.uk \\ * Correspondence: kongxiaodan1992@163.com
}

Received: 18 November 2019; Accepted: 18 December 2019; Published: 20 December 2019

\begin{abstract}
Knowledge sharing behavior based on the cluster innovation network has become the primary measure for enterprises to realize sustainable innovation. In order to promote the proactive knowledge sharing behavior among enterprises in the long term, the dynamic evolutionary process and law of knowledge sharing in the network need to be further studied. As different from the hypothesis of the rational man in the classical game theory, this paper establishes an evolutionary game model of knowledge sharing behavior in the cluster innovation network based on the evolutionary game theory, and discusses how the bounded rational enterprises can achieve the evolutionary equilibrium through continuously adaptive learning and strategy optimization, further explores the influence factors on the evolutionary trajectory. Combined with mathematical derivation and simulation analysis, the following results are obtained: over time, the dynamic evolution of knowledge sharing behavior in the cluster innovation network is influenced by initial states of the system, but can always reach the evolutionary stable equilibrium; factors such as synergy revenue have a positive impact on the evolutionary results, while factors such as opportunity interest have a negative impact on the evolutionary results; the factor of revenue distribution has a U-shape relationship with the evolutionary results, and the factor of direct revenue has no effect on the results. The results are expected to have an implication for improving the sustainable innovation development of enterprises in the cluster innovation network.
\end{abstract}

Keywords: knowledge sharing behavior; dynamic evolution; cluster innovation network; evolutionary game theory; enterprises sustainable innovation

\section{Introduction}

The development of modern enterprises is inseparable from innovation. Knowledge, as an important strategic resource, is one irreplaceable ingredient for enterprises to realize innovation [1]. With the increasingly complicated market demands, more and more enterprises forming the cluster network employ the collaborative approach such as knowledge sharing to increase benefits [2]. Meanwhile, one main feedback of these benefits is knowledge innovation [3], that appears as the reduction of repeated efforts to acquire valuable knowledge, prevention of the uncertain risks of knowledge development, and production of new knowledge through knowledge exchange and learning [4]. Although there are always competitions that make enterprises conservative and closed to each other, the benefits brought by knowledge sharing would outweigh the closed benefits in the long term. Therefore, knowledge innovation is of great significance to the development of an enterprise. 
If an enterprise expects to maintain its core competitiveness sustainably, it should continuously realize knowledge innovation, that is, constantly adopt knowledge sharing strategy to obtain the inexhaustible power of sustainable innovation [5].

Compared with traditional innovation that involves only one enterprise performing closed innovation [6], the open innovation [7] involving multiple enterprises has the advantages of risk sharing, benefit win-win, and sustainable innovation, etc., attracting more and more enterprises to join in and thus forming a multi-subject collaborative network-the cluster innovation network [8]. In the process of open innovation, knowledge, as the most important innovation resource, not only realizes the sustainable innovation within a single network subject, but also realizes the sustainable innovation among different network subjects through the cluster innovation network so as to accelerate the learning process of each network subject and improve the knowledge stock of the whole network. Therefore, under the backgrounds of global informatization and economization, in order to maintain the core competitiveness and run ahead of other competitors, enterprises need to transform their innovation mode from self-enclosed innovation to open-minded innovation and constantly to learn the knowledge which is related to their sustainable innovation development as much as possible, to carry out knowledge sharing. In terms of industrial production, the manufacture of either Boeing 787 or Airbus 380 has engaged more than 400 enterprises, and the research and development (R\&D) institutions' participation [9]; nevertheless, even the manufacture of small products such as iPhone has integrated dozens of enterprises' research outcomes.

The essence of innovation activities is sustainable creation of knowledge. Successful knowledge sharing behavior can usher the application of knowledge among enterprises. According to the theories of "resource-based view" and "knowledge-based view" [10,11], knowledge is the core strategic resource of an enterprise, and the knowledge sharing behavior based on the cluster innovation network platform can be an important approach for enterprises to bridge the knowledge gap and realize knowledge innovation [12]. Previous research identifies that how to achieve knowledge sharing is one of the biggest challenges for innovation management [13]. To maintain competitiveness and achieve sustainable growth, companies must constantly absorb existing knowledge and create new knowledge through knowledge sharing behavior [14]. Following this, how to facilitate efficient and sustainable knowledge sharing [15] to promote the evolution and stability of cluster innovation network has become one core problem in innovation management.

As different from simple market transactions, the knowledge sharing behavior faces both risks and opportunities. On the one hand, due to the complexity of knowledge itself and the risk of knowledge sharing, there are some barriers to knowledge sharing among enterprises, such as the loss of competitiveness caused by core knowledge leakage [16,17], free-riding behavior [18], and other trust problems [19], which hampers the knowledge sharing between enterprises. On the other hand, each member in the cluster innovation network has its own expectation to maximize earnings. However, if each network member only cares about its own benefit and takes opportunism behavior, the final result is bound to be lose-lose. The standpoint of cluster innovation network is a win-win situation where the common benefits of all network members can be maximized, rather than each network member pursuing its own maximum benefit. In order to get the Pareto optimality of the whole network in the long term, the way to break through the dilemma of knowledge concealing behavior-and promote the proactive knowledge sharing among enterprises-has become a hot topic in the field of knowledge management [20].

The knowledge sharing behavior in the cluster innovation network is a process of mutual game among cooperative enterprises. The knowledge sharing behavior of one enterprise in the network will more or less influence the behavior of the other enterprises, and, in return, be constrained by the others. In addition, one enterprise cannot obtain all the information from the complicated environment to make a global-optimal strategy, and can only adopt a heuristic method according to the limited information and make local-optimal decisions. This kind of decision-making process embodies the individual's bounded rationality [21]. Therefore, the dynamic evolution of knowledge sharing behavior among 
enterprises in the cluster innovation network has two elements of evolutionary game theory [22]: (1) In the cluster innovation network, each enterprise can play games with all the other individuals in the network. The cluster innovation network composed of enterprises has the characteristics of spatial evolution. (2) The network subjects have bounded rationality. According to the local information, enterprises can continuously optimize their own strategies through repeated game process of heuristics. Hence, the evolution of knowledge sharing behavior in the whole network could be observed over time with the evolutionary game method.

Based on the above, this paper discusses how to integrate innovation resources into the cluster innovation network so as to accelerate the innovation process and reduce innovation risks through constant knowledge sharing among enterprises. In order to promote the proactive and sustainable knowledge sharing behavior among enterprises in the long term, both the dynamic evolutionary process and law of knowledge sharing in the network need to be further studied. To capture the interactive behavior of enterprises, a new model is put forward in this paper by using evolutionary game theory, based on which the evolutionary mechanism of the knowledge sharing behavior in the cluster innovation network is investigated. First of all, this paper refers to the previous research studying the critical factors that affect the enterprises' knowledge sharing behavior, and then extracts and defines the basic cost-benefit factors, fair distribution factors, external incentive, and penalty factors that are crucial to knowledge sharing. By analyzing the game payoff matrix of knowledge sharing strategies, the evolutionary game model of knowledge sharing behavior in cluster innovation network is established. Based on the replicator dynamic equation, the evolutionary trajectory of knowledge sharing behavior in the network is determined. The last, the impact of each factor on the evolutionary trajectory is simulated.

This remainder of this paper is structured as follows. Section 2 reviews the relevant literature on knowledge sharing behavior among enterprises in the cluster innovation network based on evolutionary game theory. Section 3 builds the evolutionary game model of knowledge sharing behavior among enterprises in the cluster innovation network and analyzes the dynamic evolution of the model. Section 4 represents the sensitivity analysis of different influence factors impacting on the evolutionary results. Section 5 offers conclusions and management implications.

\section{Literature Review}

\subsection{Cluster Innovation Network and Knowledge Innovation}

Cluster innovation network refers to the multi-agent collaborative innovation organization established by knowledge sharing and technical cooperation among enterprises [23]. Its specific operation mode exists in the purpose of sustainable knowledge innovation, risk sharing, and mutual benefit through major projects, and co-construction of laboratories and business incubators by enterprises, universities and research institutions. The concept of the cluster innovation network was firstly proposed by Debresson and Amesse [24] to express the networks of innovators. Subsequently, a lot of studies redefined the cluster innovation network from different perspectives such as strategic management and organizational behavior. Despite various studies, the essence of the cluster innovation network is an organization emerging from the innovation subject to adapt to the complexity of innovation. Undoubtedly, the cluster innovation network is composed of various relationships among network subjects, and its main function is to provide a platform for sustainable knowledge innovation.

Knowledge sharing behavior can help enterprises acquire new resources from the outside to realize sustainable knowledge innovation that plays an irreplaceable role in modern enterprise management theory [25]. The importance of knowledge sharing behavior is discussed by scholars from different perspectives: "Resource-based theory" believes that acquiring new knowledge and information resources from the outside is the key approach for enterprises to enhance their innovation potential [26]. "Knowledge base theory" holds that knowledge is an extremely precious enterprise resource, and the survival and development of enterprises cannot be separated from knowledge 
acquisition [27]. "Transaction cost theory" emphasizes the minimization of exchange cost and the maximization of economic benefits and all participants of knowledge sharing should also pay attention to the importance of rules, contracts, and relationship norms in the transaction process [28]. "Social exchange theory" holds that interpersonal interaction is a process in which participants exchange valuable resources while carrying out relevant activities with each other. The core of this theory is that the relationship between enterprises follows the principle of reciprocity, and the exchange of rewards not only includes financial returns, but also non-financial returns such as trust, self-esteem, and prestige [29]. "Trust theory" holds that through strong identification trust, members are willing to put efforts to the investigation of emotional interactions with others and will be more likely to maintain the community by continuous interaction with others [30]. Following this theory, a critical condition for knowledge sharing would be the establishment of trust between sharing parties [31], as inter-organizational trust would be able to encourage information sharing, to create benefits through negotiations, and to generate familiarity among enterprises through interpersonal interactions [32].

In conclusion, with the deepening of global integration and the more and more complicated internal and external environment, it is urgent for managers to use new theories and methods to examine the existing problems of knowledge sharing in cluster innovation network. In order to optimize and promote the upgrading of innovative cluster, it is necessary to rely on the network theory to investigate how cluster innovation network strengthen the innovation foundation by integrating innovation resources. The above plays an important role in the development of national economy and enterprise sustainable innovation.

\subsection{Knowledge Sharing Behavior among Enterprises}

At present, researches on knowledge sharing behavior of enterprises mainly include two perspectives: influence factors and process mechanism. Scholars have studied the influence factors of knowledge sharing based on factor theory [33], including individual attributes (e.g., trust, willingness and ability of knowledge senders and receptors), knowledge characteristics and situational factors of knowledge sharing by using the methods of empirical studies. Hashim and Tan [34] use a structural equation modelling technique to examine the mediating role of identification trust and affective commitment on members' continuous knowledge sharing intention within business online communities. They find that continuous knowledge sharing intention is partially mediated by affective commitment and identification trust. Cheng et al. [35] examine how trust interacts with factors affecting inter-organizational knowledge sharing in green supply chains from 288 major green manufacturing firms in Taiwan and find that trust is the pivot of the factors influencing inter organizational knowledge sharing. From the environmental and object perspectives, Zhang and $\mathrm{Ng}$ [36] proposes that the factors affecting individual knowledge sharing intention are trust, motivation and interpersonal relationship by conducting questionnaire survey in construction teams of Hong Kong. Through analyzing the influence factors of knowledge transfer in R\&D alliances, Cummings and Teng [37] find that knowledge characteristics, knowledge absorption capacity, and governance structure are significant, and then put forward corresponding suggestions for knowledge cooperation in R\&D alliances. Ahn and Kim [38] conduct structural equation modeling (SEM) analysis to analyze the data of 319 manufacturing firms in South Korea, and the results show that social capital plays a mediating role in the relationship between the level of individual knowledge of employees and organizations' capabilities. Based on multiple case studies of knowledge leakage in joint R\&D projects in large firms in Sweden, Frishammar et al. [19] propose that the dark side of knowledge transfer is knowledge leakage, which will deter knowledge sharing.

To sum up, the influence factors of knowledge sharing can be roughly divided into incentive factors and penalty factors, but such classification is lack of hierarchy. In addition to the basic factors of cost-benefit, the managers of modern organizations should also consider the external mechanisms such as the fair distribution mechanism, incentive, and penalty mechanism. Rather than simply discussing the influence factors, attention should be paid to the knowledge sharing behavior among enterprises 
under the interaction of different situations over time. The mathematical model can also be used to deeply understand the decision-making process of knowledge sharing participants from the micro perspective, getting rid of the dilemma in cooperative innovation among enterprises.

More and more scholars use classical game theory or numerical simulation to analyze the process of knowledge sharing behavior. Using classical game theory to analyze the economic utility of enterprise knowledge acquisition is commonly used by economists. Samaddar and Kadilyala [39] explore the conditions of resource sharing and model the collaboration for knowledge creation as a Stackelberg leader-follower game, finding that it is important to maintain an optimal ratio between the leader's and follower's marginal gains for the formation and continuation of the collaboration. Lin and Wang [40] target dynamic knowledge sharing in a construction project team, constructing a dynamic incentive model framework. They find that the participants will share the cumulative amount of knowledge in the leader-follower differential games; the optimal profits of agents and principal are increased as time progressed, and the agents' effort level of knowledge sharing eventually tending to stability. Jiang and Hao [41] establish a two stages decision-making model to investigate the influence of ownership level and learning ability on the stability of technology innovation alliance from the perspective of knowledge transfer. The Cournot-Nash equilibrium in their model can reveal when the parties decide to maintain or terminate the alliance.

Furthermore, some scholars have adopted simulation methods to discuss the knowledge sharing behavior. Compared with the classical game theory, the simulation method pays more attention to the dynamic process of knowledge sharing. For example, Wang [42] constructs an agent dynamics agent-based model to analyze the exchange and reciprocal mechanism behind individual knowledge transfer activities as well as their impact on the individual knowledge transfer networks. The results demonstrate that the exchange mechanism can improve the knowledge levels of the network members. Based on the existing epidemic models, Li et al. [43] consider the influence of individual forgetting ability and leader's inspiration ability on the dynamic mechanism of knowledge sharing diffusion. By constructing knowledge diffusion mechanism with self-learning ability, Wang et al. [44] discuss its evolutionary effect in complex network structure. Zhu and Ma [45] propose a knowledge sharing model considering time-varying information channels and investigated the knowledge evolution in different network structures. Considering the knowledge forgetfulness, Cao et al. [46] establish a knowledge transmission model in which the level of forgetfulness depended mainly on the number of neighboring individuals who possess knowledge. Through developing a game model for knowledge-sharing strategies at the interpersonal level, Ho et al. [47] assess the dynamics of individual behavior within organizations in terms of knowledge sharing.

The above studies have laid a foundation of knowledge sharing, but have not considered the changes and dynamic evolution of group behavior in micro-level. Firstly, it is impossible for game participants to fully understand each other's information in reality, and there are certain risks and losses in the process of the game. Secondly, the knowledge sharing behavior is a game of incomplete information, but the enterprise entity has the ability to learn and optimize its own strategy. Based on trust and synergy revenue, the participants will maintain a long-term and stable cooperative relationship, that is, the knowledge sharing behavior can also be regarded as an infinitely repeated game. Finally, the traditional research objects mainly focus on the knowledge sharing behavior either between internal R\&D departments in a single enterprise or two enterprises, while the research based on cluster innovation network is relatively deficient.

\subsection{Application of Evolutionary Game Theory}

Evolutionary game theory can well explain the long-term economic and sustainable trade relations among a large number of individuals in the living nature and the real society [48]. Evolutionary game theory has been widely used in decision-making, production management, project management, supply chain management, social networks, etc. Specifically, evolutionary game theory focuses on how bounded rationality individuals optimize their benefits through adaptive learning over time in 
the process of repeated games. Eventually, a certain type of strategy, which is a subset of the Nash equilibrium, will reach equilibrium in the population and is called an evolutionary stable strategy. At the same time, evolutionary game theory emphasizes the long-term and repetitive game behavior.

On the one hand, from cooperation concept, enterprise joining the cluster innovation network has its own rational expectation to maximize benefit. However, if the network members only consider their own desire without considering other partners' reaction, the final outcome would inevitably go to lose-lose. The idea of establishing cluster innovation network is win-win, that is, all participants are satisfied, rather than one participant maximizes its own benefit at the risk of revenge. This principle of satisfaction is in accordance with the game theory to explain the multi-cooperative game, and the key difference from the one-time stochastic game is the introduction of rational expectation [49]. On the other hand, from cooperation behavior, the knowledge sharing behavior of a certain enterprise has more or less influence on the other enterprises, which in turn is more or less restricted by other enterprises. Therefore, the knowledge sharing behavior in cluster innovation network is a mutual game among enterprises.

In a cluster innovation network, the enterprises do not have enough ability to choose the best strategy, but have the ability to learn and update the strategy. Meanwhile, the enterprises usually adopt heuristic method according to the local information and thus make satisfactory decisions. This decision-making process reflects the bounded rationality of individuals. Because the differences of participants will lead to different sharing motivation, willingness, benefits, costs, etc., the study of knowledge sharing behavior based on evolutionary game theory is helpful to understand the decision-making process of knowledge sharing from micro-level. Through examining the evolutionary process of knowledge sharing among users of the social commerce, Jiang et al. [50] build an evolutionary game model to depict knowledge sharing phenomenon in the virtual community and develop a mixed learning algorithm based on individual user's historical game strategy, neighborhood user's strategy, and information noise. Chen [51] establishes an asymmetrical evolutionary game model of enterprise supervision to regard contextual factors and individual factors as risk preferences of knowledge wForkers. By using evolutionary game model, Liu et al. [52] analysis the best knowledge-sharing strategies for firms to be engaged in supply chain collaborative innovation. Erkal and Minehart [53] build a theoretical foundation for the dynamics of knowledge sharing in private industry, and examine the impact of inter-firm competition on knowledge sharing behavior in R\&D cooperation.

Accordingly, targeting at the limitations of the existing research, this paper, from the process perspective, integrates the relevant factors in the knowledge sharing process into the payoff function, and constructs the game payoff matrix. Based on evolutionary game theory, the evolutionary stability equilibrium of knowledge sharing behavior is discussed. On this basis, in order to show the learning behavior of bounded rational enterprises, the sensitivity of various influence factors and the dynamic process of knowledge sharing behavior are simulated using Matlab. To sum up, this paper mainly studies the evolutionary pattern of knowledge sharing behavior among a large number of cluster enterprises by answering the following questions: what factors have an impact on the evolution of knowledge sharing; how is the impact of each factor; how to control or adjust these influence factors to improve the level of knowledge sharing among enterprises in the cluster innovation network? On this account, the evolution pattern of knowledge sharing behavior among enterprises in cluster innovation network is further revealed.

\section{Model Construction}

Based on evolutionary game theory, this paper integrates the influence factors into the payoff function and constructs the game payoff matrix of knowledge sharing. Then the dynamic evolution of knowledge sharing behavior among enterprises are investigated by mathematical derivation and simulation analysis.

Our model is built upon a number of assumptions: 
Assumption 1. The cluster innovation network is a uniformly mixed network, and one individual enterprise can play games with the other individual enterprises in the network.

Assumption 2. Any individual enterprise in cluster innovation network has the ability to learn to imitate and choose their own strategies, and each participant of the game constantly adjust their strategies according to the changes of the other participants' strategies, until the evolution is stable.

\subsection{Model Variables and Game Payoff Matrix}

Factors affecting the enterprise knowledge sharing behavior are as below:

$\alpha_{1}, \alpha_{2}$ : Direct revenue coefficient of knowledge sharing. The coefficients each corresponds to an enterprise (Enterprise 1 and Enterprise 2). Each direct revenue coefficient represents the ability for one enterprise to absorb the shared knowledge from the other, and this ability is closely related to factors such as the enterprise's knowledge stock and autonomous learning ability.

$k_{1}, k_{2}$ : The amount of shared knowledge. The variables each represents the amount of knowledge that one enterprise is willing to share with the other. The greater the amount of knowledge one enterprise is willing to share, the greater the revenue the other can obtain.

$\beta_{1}, \beta_{2}$ : Synergy revenue coefficient of knowledge sharing. The coefficients each corresponds to an enterprise (Enterprise 1 and Enterprise 2). Each synergy revenue coefficient is closely related to the degrees of knowledge complementarity and trust between two enterprises. Due to the difference of knowledge, Enterprise 1 and Enterprise 2 will generate new knowledge and collaborative revenue through knowledge sharing.

$\theta$ : Synergy revenue distribution coefficient between two enterprises. The size of this coefficient reflects the proportionality and fairness of revenue distribution, which will further affect the enthusiasm of knowledge sharing in the next stage.

$m, n$ : Elastic coefficients of the amount of shared knowledge between two enterprises. Where $m+n=1(m, n>0)$.

$r_{1}, r_{2}$ : Risk coefficient of knowledge sharing. The coefficients each corresponds to an enterprise (Enterprise 1 and Enterprise 2). Risk coefficients reflect the leakage of core knowledge and the reduction of knowledge competitiveness. The size of these coefficients is closely related to the degree of knowledge complementarity, knowledge relevance and the competitors' knowledge reasoning ability.

$c_{1}, c_{2}$ : Knowledge sharing cost. The costs each corresponds to an enterprise (Enterprise 1 and Enterprise 2), which includes the opportunity cost, technical cost, material cost and time cost in the process of knowledge sharing.

$\lambda$ : Incentive revenue of knowledge sharing. It represents the incentive revenue setting up by the third party (e.g., certain organizations, government) to encourage enterprises to proactively adopt knowledge sharing strategy.

$\eta_{1}, \eta_{2}$ : Opportunity benefit coefficient. The coefficients each corresponds to an enterprise (Enterprise 1 and Enterprise 2), which represents the extra benefit emerging from the situation where one enterprise does not adopt knowledge sharing while the other does. This extra benefit is the embodiment of the opportunity benefit and also a kind of free-riding and moral hazard behavior.

$\rho$ : Penalty cost. It refers to the punishment imposed by certain organizations or the government on enterprises that do not adopt knowledge sharing strategy. The penalty cost is a comprehensive metric including not only the economic losses but also the non-economic losses such as reputation and image.

The above variables are designed systemically by taking into account both basic cost-benefit variables (direct revenue of knowledge sharing $\alpha k$, synergy revenue of knowledge sharing $\beta k_{1}^{m} k_{2}^{n}$, opportunity benefit $\eta k$, knowledge sharing cost $c k$, knowledge sharing risk $r k$ ) and external mechanism variables (the distribution of synergy revenue $\theta$, incentive revenue $\lambda$, and penalty cost $\rho$ ). 
Using the above mentioned factors, any two participants in the cluster innovation network play the knowledge sharing game and thus the knowledge sharing game payoff matrix can be established as shown in Table 1.

Table 1. Knowledge sharing game payoff matrix of enterprises in cluster innovation network.

\begin{tabular}{|c|c|c|c|}
\hline & & \multicolumn{2}{|c|}{ Enterprise 2} \\
\hline & & Knowledge Sharing & Knowledge-Non-Sharing \\
\hline \multirow{2}{*}{ Enterprise 1} & $\begin{array}{l}\text { Knowledge } \\
\text { Sharing }\end{array}$ & $\begin{array}{c}\alpha_{1} k_{2}+\theta \beta_{1} k_{1}^{m} k_{2}^{n}-r_{1} k_{1}-c_{1}+\lambda k_{1} \\
\alpha_{2} k_{1}+(1-\theta) \beta_{2} k_{1}^{m} k_{2}^{n}-r_{2} k_{2}-c_{2}+\lambda k_{2}\end{array}$ & $\begin{array}{l}-r_{1} k_{1}-c_{1}+\lambda k_{1} \\
\alpha_{2} k_{1}+\eta_{2} k_{1}-\rho\end{array}$ \\
\hline & $\begin{array}{l}\text { Knowledge- } \\
\text { Non-Sharing }\end{array}$ & $\begin{array}{l}\alpha_{1} k_{2}+\eta_{1} k_{2}-\rho \\
-r_{2} k_{2}-c_{2}+\lambda k_{2}\end{array}$ & $\begin{array}{l}-\rho \\
-\rho\end{array}$ \\
\hline
\end{tabular}

The payoff functions of both participants of the game can be sorted into the following three cases:

(1) When both Enterprise 1 and Enterprise 2 adopt knowledge sharing strategy, the payoff of Enterprise 1 is $\alpha_{1} k_{2}+\theta \beta_{1} k_{1}^{m} k_{2}^{n}-r_{1} k_{1}-c_{1}+\lambda k_{1}$, which includes direct revenue $\alpha_{1} k_{2}$, synergy revenue $\theta \beta_{1} k_{1}^{m} k_{2}^{n}$, incentive revenue $\lambda k_{1}$, knowledge sharing risk $r_{1} k_{1}$, and knowledge sharing cost $c_{1}$. Similarly, the payoff of Enterprise 2 is $\alpha_{2} k_{1}+(1-\theta) \beta_{2} k_{1}^{m} k_{2}^{n}-r_{2} k_{2}-c_{2}+\lambda k_{1}$.

(2) When Enterprise 1 adopts knowledge sharing strategy while Enterprise 2 adopts the knowledge-non-sharing strategy, the payoff of Enterprise 1 is $-r_{1} k_{1}-c_{1}+\lambda k_{1}$, which includes knowledge sharing risk $r_{1} k_{1}$, knowledge sharing $\operatorname{cost} c_{1}$, and knowledge sharing incentive revenue $\lambda k_{1}$. The payoff of Enterprise 2 is $\alpha_{2} k_{1}+\eta k_{1}-\rho$, including direct revenue $\alpha_{2} k_{1}$, opportunity benefit $\eta k_{1}$ and penalty cost $\rho$. Similarly, when Enterprise 1 adopts the knowledge- non-sharing strategy and Enterprise 2 adopts the knowledge sharing strategy, their revenues are $\alpha_{1} k_{2}+\eta k_{2}-\rho$ and $-r_{2} k_{2}-c_{2}+\lambda k_{2}$, respectively.

(3) When Enterprise 1 and Enterprise 2 both adopt the knowledge-non-sharing strategy, both of them have no revenues and pay the corresponding penalty cost $\rho$.

\subsection{Analysis of Model Dynamic Evolution}

\subsubsection{Dynamic Evolutionary Equilibrium and Stability}

Enterprises in the cluster innovation network have bounded rationality, and one game participant can adjust its own strategies according to the changes of the others' strategies until the evolutionary equilibrium is reached. Based on Table 1, assume the proportion of adopting knowledge sharing strategy for Enterprise 1 is $x$, and the proportion of adopting knowledge-non-sharing strategy is $1-x$. Similarly, assume the proportion of adopting knowledge-sharing strategy for Enterprise 2 is $y$, and the proportion of adopting knowledge-non-sharing strategy is $1-y$. After $x$ and $y$ are initialized, the strategies of the network subjects will keep changing in the process of continuous imitation and learning. The replicator dynamics Equation [54] is often used in previous research to analyze random matching games among a large number of members; thus, this Equation is also adopted to solve the approximate solution of evolutionary equilibrium in cluster innovation network.

When Enterprise 1 chooses knowledge sharing strategy, its average revenue is defined in Equation (1):

$$
U_{1}=y\left(\alpha_{1} k_{2}+\theta \beta_{1} k_{1}^{m} k_{2}^{n}-r_{1} k_{1}-c_{1}+\lambda k_{1}\right)+(1-y)\left(-r_{1} k_{1}-c_{1}+\lambda k_{1}\right)=y\left(\alpha_{1} k_{2}+\theta \beta_{1} k_{1}^{m} k_{2}^{n}\right)-r_{1} k_{1}-c_{1}+\lambda k_{1}
$$

The average revenue of Enterprise 1 choosing knowledge-non-sharing strategy is:

$$
U_{1}^{\prime}=y\left(\alpha_{1} k_{2}+\eta k_{2}-\rho\right)+(1-y)(-\rho)=y\left(\alpha_{1} k_{2}+\eta k_{2}\right)-\rho
$$


Combining the above two Equations (1) and (2), the average total revenues of Enterprise 1 is:

$$
\overline{U_{1}}=x U_{1}+(1-x) U_{1}^{\prime}=x y\left(\theta \beta_{1} k_{1}^{m} k_{2}^{n}-\eta k_{2}\right)-x\left(r_{1} k_{1}+c_{1}-\lambda k_{1}-\rho\right)+y\left(\alpha_{1} k_{2}+\eta k_{2}\right)-\rho
$$

When Enterprise 2 chooses knowledge-sharing strategy, its average revenue is defined in Equation (4):

$$
\begin{aligned}
U_{2} & =x\left(\alpha_{2} k_{1}+(1-\theta) \beta_{2} k_{1}^{m} k_{2}^{n}-r_{2} k_{2}-c_{2}+\lambda k_{2}\right)+(1-x)\left(-r_{2} k_{2}-c_{2}+\lambda k_{2}\right) \\
& =x \alpha_{2} k_{1}+x(1-\theta) \beta_{2} k_{1}^{m} k_{2}^{n}-r_{2} k_{2}-c_{2}+\lambda k_{2}
\end{aligned}
$$

The average revenue of Enterprise 2 choosing knowledge-non-sharing strategy is:

$$
U_{2}^{\prime}=x\left(\alpha_{2} k_{1}+\eta k_{1}-\rho\right)+(1-x)(-\rho)=x \alpha_{2} k_{1}+x \eta k_{1}-\rho
$$

Combining the above two Equations (4) and (5), the average total revenues of Enterprise 2 is:

$$
\overline{U_{2}}=y U_{2}+(1-y) U_{2}^{\prime}=x y\left[(1-\theta) \beta_{2} k_{1}^{m} k_{2}^{n}-\eta k_{1}\right]-y\left(r_{2} k_{2}+c_{2}-\lambda k_{2}-\rho\right)+x\left(\alpha_{2} k_{1}+\eta k_{1}\right)-\rho
$$

The replicator dynamics Equation of Enterprise 1 is:

$$
\frac{d x}{d t}=x\left(U_{1}-\overline{U_{1}}\right)=x(1-x)\left(y \theta \beta_{1} k_{1}^{m} k_{2}^{n}-y \eta k_{2}-r_{1} k_{1}-c_{1}+\lambda k_{1}+\rho\right)
$$

The replication dynamic Equation of Enterprise 2 is:

$$
\frac{d y}{d t}=y\left(U_{2}-\overline{U_{2}}\right)=y(1-y)\left(x(1-\theta) \beta_{2} k_{1}^{m} k_{2}^{n}-x \eta k_{1}-r_{2} k_{2}-c_{2}+\lambda k_{2}+\rho\right)
$$

Assume $\frac{d x}{d t}=0$, and then obtain $x^{*}=0, x^{*}=1$ and $y^{*}=\frac{r_{1} k_{1}+c_{1}-\lambda k_{1}-\rho}{\theta \beta_{1} k_{1}^{m} k_{2}^{n}-\eta k_{2}}$;

Assume $\frac{d y}{d t}=0$, and then obtain $y^{*}=0, y^{*}=1$ and $x^{*}=\frac{r_{2} k_{2}+c_{2}-\lambda k_{2}-\rho}{(1-\theta) \beta_{2} k_{1}^{k} k_{2}^{n}-\eta k_{1}}$.

Finally, five network evolution equilibrium points are obtained as $(0,0),(0,1),(1,0),(1,1)$ and $\left(\frac{r_{2} k_{2}+c_{2}-\lambda k_{2}-\rho}{(1-\theta) \beta_{2} k_{1}^{m} k_{2}^{n}-\eta k_{1}}, \frac{r_{1} k_{1}+c_{1}-\lambda k_{1}-\rho}{\theta \beta_{1} k_{1}^{m} k_{2}^{n}-\eta k_{2}}\right)$. The Jacobian matrix composed of Equations (7) and (8) is:

$$
J=\left[\begin{array}{l}
(1-2 x)\left(y q b_{1} k_{1}^{m} k_{2}^{n}-y h k_{2}-r_{1} k_{1}-c_{1}+l k_{1}+r\right) x(1-x)\left(q b_{1} k_{1}^{m} k_{2}^{n}-h k_{2}\right) \\
y(1-y)\left[(1-q) b_{2} k_{1}^{m} k_{2}^{n}-h k_{1}\right](1-2 y)\left[x(1-q) b_{2} k_{1}^{m} k_{2}^{n}-x h k_{1}-r_{2} k_{2}-c_{2}+l k_{2}+r\right]
\end{array}\right]
$$

As shown in Table 2, the stability of the five equilibrium points can be judged by calculating the determinant and trace of the Jacobian matrix of the system.

The criterion for the stability of equilibrium points in the Jacobian matrix is as follows: if Det $J>0$ and $\operatorname{Tr} J<0$, the equilibrium point reaches the stable state, so the equilibrium point is evolutionary stable strategy (ESS); if $\operatorname{Det} J \geq 0$ and $\operatorname{Tr} J>0$, the equilibrium point is unstable; if $\operatorname{Det} J>0$ and $\operatorname{Tr} J=0$, the equilibrium point is neutral; if $\operatorname{Det} J<0$, the equilibrium point is saddle. On this basis, the stability of the equilibrium points is analyzed in Table 3 in terms of four scenarios as: $0<x^{*}<1,0<y^{*}<1$; $x^{*}>1,0<y^{*}<1 ; 0<x^{*}<1, y^{*}>1 ; x^{*}>1, y^{*}>1$. 
Table 2. Determinant and trace of the Jacobian matrix.

\begin{tabular}{|c|c|}
\hline $\begin{array}{l}\text { Equilibrium } \\
\text { Point }\end{array}$ & The Determinant and Trace of $J$ \\
\hline$O(0,0)$ & $\begin{array}{c}\operatorname{DetJ}=\left(-r_{1} k_{1}-c_{1}+\lambda k_{1}+\rho\right)\left(-r_{2} k_{2}-c_{2}+\lambda k_{2}+\rho\right) \\
\operatorname{TrJ}=\left(-r_{1} k_{1}-c_{1}+\lambda k_{1}+\rho\right)+\left(-r_{2} k_{2}-c_{2}+\lambda k_{2}+\rho\right)\end{array}$ \\
\hline$B(0,1)$ & $\begin{array}{l}\operatorname{Det} J=\left(\theta \beta_{1} k_{1}^{m} k_{2}^{n}-\eta k_{2}-r_{1} k_{1}-c_{1}+\lambda k_{1}+\rho\right) \cdot\left(r_{2} k_{2}+c_{2}-\lambda k_{2}-\rho\right) \\
\operatorname{TrJ}=\left(\theta \beta_{1} k_{1}^{m} k_{2}^{n}-\eta k_{2}-r_{1} k_{1}-c_{1}+\lambda k_{1}+\rho\right)+\left(r_{2} k_{2}+c_{2}-\lambda k_{2}-\rho\right)\end{array}$ \\
\hline$C(1,0)$ & $\begin{array}{l}\operatorname{Det} J=\left(r_{1} k_{1}+c_{1}-\lambda k_{1}-\rho\right) \cdot\left[(1-\theta) \beta_{2} k_{1}^{m} k_{2}^{n}-\eta k_{1}-r_{2} k_{2}-c_{2}+\lambda k_{2}+\rho\right] \\
\operatorname{TrJ}=\left(r_{1} k_{1}+c_{1}-\lambda k_{1}-\rho\right)+\left[(1-\theta) \beta_{2} k_{1}^{m} k_{2}^{n}-\eta k_{1}-r_{2} k_{2}-c_{2}+\lambda k_{2}+\rho\right]\end{array}$ \\
\hline$A(1,1)$ & $\begin{array}{c}\operatorname{Det} J=\left(\theta \beta_{1} k_{1}^{m} k_{2}^{n}-\eta k_{2}-r_{1} k_{1}-c_{1}+\lambda k_{1}+\rho\right) \cdot\left[(1-\theta) \beta_{2} k_{1}^{m} k_{2}^{n}-\eta k_{1}-r_{2} k_{2}-c_{2}+\lambda k_{2}+\rho\right] \\
\operatorname{TrJ}=-\left(\theta \beta_{1} k_{1}^{m} k_{2}^{n}-\eta k_{2}-r_{1} k_{1}-c_{1}+\lambda k_{1}+\rho\right)-\left[(1-\theta) \beta_{2} k_{1}^{m} k_{2}^{n}-\eta k_{1}-r_{2} k_{2}-c_{2}+\lambda k_{2}+\rho\right]\end{array}$ \\
\hline$E\left(x^{*}, y^{*}\right)$ & $\begin{aligned} \operatorname{Det} J= & \left(1-2 x^{*}\right)\left(y^{*} \theta \beta_{1} k_{1}^{m} k_{2}^{n}-y^{*} \eta k_{2}-r_{1} k_{1}-c_{1}+\lambda k_{1}+\rho\right)\left(1-2 y^{*}\right) \\
& {\left[\begin{array}{l}\left.x^{*}(1-\theta) \beta_{2} k_{1}^{m} k_{2}^{n}-x^{*} \eta k_{1}-r_{2} k_{2}-c_{2}+\lambda k_{2}+\rho\right]-x^{*}\left(1-x^{*}\right) \\
\\
\left(\theta \beta_{1} k_{1}^{m} k_{2}^{n}-\eta k_{2}\right) y^{*}\left(1-y^{*}\right)\left[(1-\theta) \beta_{2} k_{1}^{m} k_{2}^{n}-\eta k_{1}\right]\end{array}\right.} \\
\operatorname{Tr} J=0 & \end{aligned}$ \\
\hline
\end{tabular}

Table 3. Stability analysis of equilibrium points.

\begin{tabular}{ccccc}
\hline Scenarios & Equilibrium Point & Det $\boldsymbol{T}$ & TrJ & Equilibrium Results \\
\hline & $O(0,0)$ & $>0$ & $<0$ & ESS \\
Scenario 1 & $B(0,1)$ & $>0$ & $>0$ & Unstable \\
$0<x^{*}<1,0<y^{*}<1$ & $C(1,0)$ & $>0$ & $>0$ & Unstable \\
& $A(1,1)$ & $>0$ & $<0$ & ESS \\
& $E\left(x^{*}, y^{*}\right)$ & $>0$ & 0 & Saddle \\
\hline Scenario 2 & $O(0,0)$ & $>0$ & $<0$ & ESS \\
$x^{*}>1,0<y^{*}<1$ & $B(0,1)$ & $<0$ & Uncertain & Saddle \\
& $C(1,0)$ & $>0$ & $>0$ & Unstable \\
& $A(1,1)$ & $<0$ & Uncertain & Saddle \\
Scenario 3 & $E\left(x^{*}, y^{*}\right)$ & $>0$ & 0 & Neutral \\
$0<x^{*}<1, y^{*}>1$ & $O(0,0)$ & $>0$ & $<0$ & ESS \\
& $B(0,1)$ & $>0$ & $>0$ & Unstable \\
& $C(1,0)$ & $<0$ & Uncertain & Saddle \\
& $A(1,1)$ & $<0$ & Uncertain & Neutral \\
\hline Scenario 4 & $E\left(x^{*}, y^{*}\right)$ & $>0$ & 0 & ESS \\
$x^{*}>1, y^{*}>1$ & $O(0,0)$ & $>0$ & $<0$ & Saddle \\
& $B(0,1)$ & $<0$ & Uncertain & Saddle \\
& $C(1,0)$ & $<0$ & Uncertain & Unstable \\
\hline & $A(1,1)$ & $>0$ & $>0$ & Saddle \\
\hline
\end{tabular}

Taking Scenario 1 as an example, solve the constraints $0<x^{*}<1,0<y^{*}<1$ and then obtain:

$$
\begin{aligned}
& \left\{\begin{array}{l}
\lambda k_{2}+\rho<r_{2} k_{2}+c_{2} \quad x^{*}>0 \\
(1-\theta) \beta_{2} k_{1}^{m} k_{2}^{n}+\lambda k_{2}+\rho>\eta k_{1}+r_{2} k_{2}+c_{2}
\end{array} \quad x^{*}<1\right. \\
& \left\{\begin{array}{cc}
\lambda k_{1}+\rho<r_{1} k_{1}+c_{2} & y^{*}>0 \\
\theta \beta_{1} k_{1}^{m} k_{2}^{n}+\lambda k_{1}+\rho>\eta k_{2}+r_{1} k_{1}+c_{1} & y^{*}<1
\end{array}\right.
\end{aligned}
$$

According to the criterion for the stability of equilibrium points:

(1) Only if $\lambda k_{1}+\rho<r_{1} k_{1}+c_{1}, \lambda k_{2}+\rho<r_{2} k_{2}+c_{2}$, the stable evolutionary equilibrium point of the matrix is $(0,0)$. This satisfies the above constraints so that $(0,0)$ is ESS. 
(2) Only if $\theta \beta_{1} k_{1}^{m} k_{2}^{n}+\lambda k_{1}+\rho<\eta k_{2}+r_{1} k_{1}+c_{1}, r_{2} k_{2}+c_{2}<\lambda k_{2}+\rho$, the stable evolutionary equilibrium point of the matrix is $(0,1)$. This satisfies the above constraints so that $(0,1)$ is not ESS.

(3) Only if $(1-\theta) \beta_{2} k_{1}^{m} k_{2}^{n}+\lambda k_{2}+\rho<\eta k_{1}+r_{2} k_{2}+c_{2}, r_{1} k_{1}+c_{1}<\lambda k_{1}+\rho$, the stable evolutionary equilibrium point of the matrix ESS is $(1,0)$. This satisfies the above constraints so that $(1,0)$ is not ESS.

(4) Only if $\theta \beta_{1} k_{1}^{m} k_{2}^{n}+\lambda k_{1}+\rho>\eta k_{2}+r_{1} k_{1}+c_{1},(1-\theta) \beta_{2} k_{1}^{m} k_{2}^{n}+\lambda k_{2}+\rho>\eta k_{1}+r_{2} k_{2}+c_{2}$, the stable evolutionary equilibrium point of the matrix is $(1,1)$. This satisfies the above constraints so that $(1,1)$ is ESS.

Based on the above, for Scenario 1, the long-term evolution results of the enterprises' knowledge sharing behavior is likely to be that all members adopt either the knowledge sharing strategy $(1,1)$ or the knowledge-non-sharing strategy $(0,0)$. Similarly, for Scenarios 2, 3, and 4 , the evolutionary equilibrium results of the system are the same as $(0,0)$.

\subsubsection{Influence of Model Variables}

According to the four Scenarios' stable results in Table 3, the corresponding evolutionary phase diagrams can be presented in Figure 1.

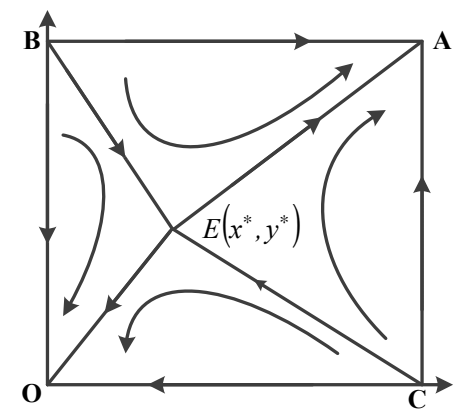

(a)

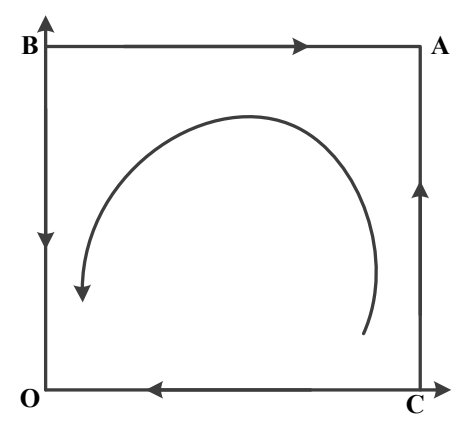

(c)



(b)

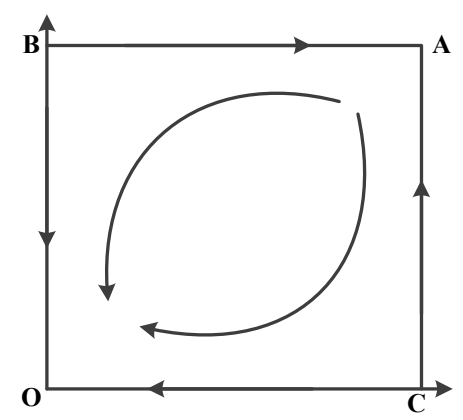

(d)

Figure 1. Evolutionary phase diagrams (Diagrams (a-d) response to Scenarios 1, 2, 3, and 4, respectively).

From the Figure 1a, line $B E C$ is the boundary where the system converges to different states. In region $B E C A$, the evolutionary game results converge to point $A(1,1)$; namely all the enterprises in the network will adopt knowledge sharing strategy over time. In region $B E C O$, the evolutionary game results converge to point $O(0,0)$; namely, all the enterprise in the network will adopt the knowledge-non-sharing strategy over time. The position of the saddle point $E\left(x^{*}, y^{*}\right)$ will affect the results of system evolution.

Assume region $B E C A$ is $S_{1}$ and region $B E C O$ is $S_{2}$. If $S_{1}$ is larger than $S_{2}$, the system will have a greater probability of convergence to $A(1,1)$. Therefore, the influence of knowledge sharing on the evolution can be determined by analyzing the factors that affect the size of $S_{1}$. 
Given $E\left(x^{*}, y^{*}\right)=\left(\frac{r_{2} k_{2}+c_{2}-\lambda k_{2}-\rho}{(1-\theta) \beta_{2} k_{1}^{m} k_{2}^{n}-\eta k_{1}}, \frac{r_{1} k_{1}+c_{1}-\lambda k_{1}-\rho}{\theta \beta_{1} k_{1}^{m} k_{2}^{n}-\eta k_{2}}\right)$, and then obtain:

$$
S_{1}=1-\frac{1}{2}\left(\frac{r_{2} k_{2}+c_{2}-\lambda k_{2}-\rho}{(1-\theta) \beta_{2} k_{1}^{m} k_{2}^{n}-\eta k_{1}}+\frac{r_{1} k_{1}+c_{1}-\lambda k_{1}-\rho}{\theta \beta_{1} k_{1}^{m} k_{2}^{n}-\eta k_{2}}\right)
$$

According to Equation (12), the factors affecting the size of $S_{1}$ can be divided into three cases: facilitating factors, impeding factors, and inverted $U$ shape factors. The facilitating factors are mainly composed of revenues, including synergy revenue $\beta$, opportunity benefit $\eta$, and incentive revenue $\lambda$. With the increase of these factors, the critical point $E\left(x^{*}, y^{*}\right)$ is moving to bottom left towards point $O(0,0)$, and the area of $B E C A$ becomes larger in Figure 1a; consequently, the probability of enterprises choosing knowledge sharing strategy becomes larger. Impeding factors are mainly composed of sharing costs, including direct cost $c$, knowledge leakage risk cost $r$, and penalty cost $\rho$. With the increase of these factors, the critical point $E\left(x^{*}, y^{*}\right)$ is moving up to top right towards point $A(1,1)$ and region $B E C A$ becomes smaller in Figure 1a; consequently, the probability of enterprises choosing knowledge-non-sharing strategy becomes larger. The factor of revenue distribution between two enterprises $\theta$ has a U-shape relationship with the evolutionary results. Only if $\theta=0.5$, the area of $B E C A$ can be a maximum, and the probability of enterprises choosing knowledge sharing strategy can be maximized.

As can be seen from Figure $1 \mathrm{~b}-\mathrm{d}$, no matter how the variables change, with time evolution, the network will converge to the $(0,0)$ state, that is, all the enterprises in the network will adopt the knowledge-non-sharing strategy.

\section{Sensitivity Analysis}

This paper uses Matlab differential equation ode45 to solve the replicator dynamics equation of the evolutionary game. The variables are initialized in Table 4, and the impact of each variable on the evolutionary trajectory in the network is analyzed as follows.

Table 4. Initial Values of Variables.

\begin{tabular}{cccccc}
\hline Variables & $k_{1}, k_{2}$ & $\alpha_{1}, \alpha_{2}$ & $\beta_{1}, \beta_{2}$ & $\theta$ & $m, n$ \\
Value & 10,10 & $0.4,0.4$ & $0.7,0.7$ & $0.5,0.5$ & $0.5,0.5$ \\
\hline Variables & $c_{1}, c_{2}$ & $\lambda$ & $\eta_{1}, \eta_{2}$ & $\rho$ & $r_{1}, r_{2}$ \\
Value & 9,9 & 0.4 & $0.15,0.1$ & 10 & $0.6,0.6$ \\
\hline
\end{tabular}

\subsection{Impact of $x$ and $y$}

Through variables setting, the saddle point of $E\left(x^{*}, y^{*}\right)$ is worked out as $(0.4,0.5)$. Randomly set 6 initial states of enterprises' knowledge sharing behavior as $(0.1,0.7),(0.3,0.4),(0.6,0.2),(0.5,0.8)$, $(0.7,0.5)$, and $(0.9,0.2)$, and then observe the dynamic evolution process of network system over time in Figure 2.

The size of the initial state $(x, y)$ reflects the enterprises' willingness to share knowledge at the beginning of evolution. It can be seen from Figure 2 that when the initial state $(x, y)$ falls into region $B E C A$, the system finally converges to $(1,1)$, that is, all the enterprises in the cluster network finally choose the knowledge sharing strategy; in contrast, when the initial state $(x, y)$ falls into region $B E C O$, the system finally converges to $(0,0)$, that is, all the enterprises in the cluster network finally choose knowledge-non-sharing strategy. 


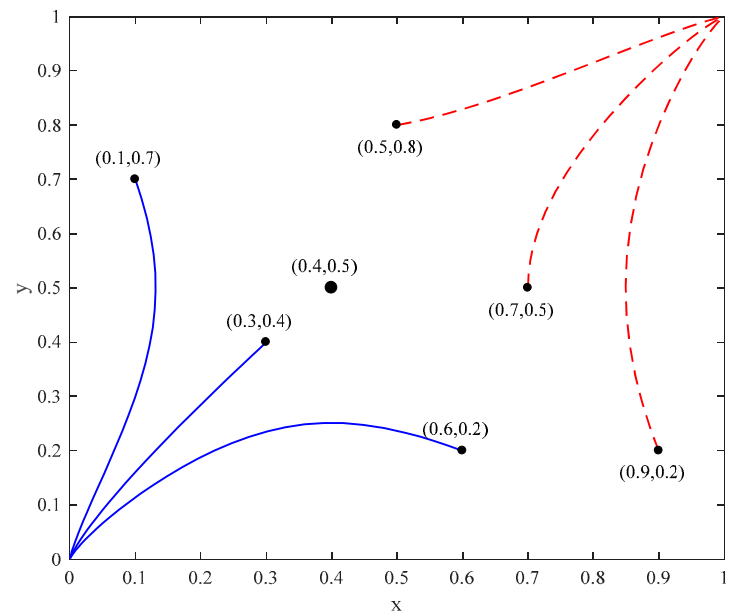

Figure 2. The dynamic evolution of knowledge sharing strategies with different initial states.

This figure verifies that the dynamic evolution of enterprises' knowledge sharing behavior is related to the initial state of the system. Because the purpose of this game is to make all participants choose the "knowledge sharing strategy" through long-term learning and strategy adjustment, enterprises should be encouraged to maintain the open mind of mutual trust in the early evolutionary game, which will be conducive to the development of the whole network's cooperative innovation.

\subsection{Impact of Synergy Revenue Coefficient $\beta_{1}$}

Assume $\beta_{1}$ takes $0.4,0.6$ and 0.8 respectively, and keep other variables unchanged to observe the dynamic evolution process of the system in Figure 3.

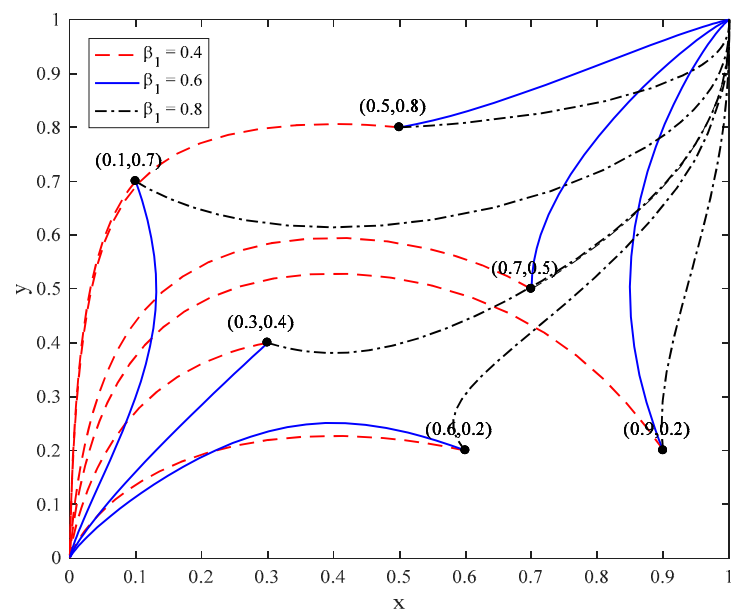

Figure 3. The dynamic evolution of knowledge sharing strategies with $\beta_{1}=0.4,0.6,0.8$.

According to Figure 3, the knowledge sharing synergy revenue coefficient $\beta_{1}$ is positively correlated with the evolutionary equilibrium of knowledge sharing behavior. When $\beta_{1}=0.6$, the initial states $(0.1,0.7),(0.3,0.4),(0.6,0.2)$ all evolve into $(0,0)$, while the initial states $(0.5,0.8),(0.7,0.5)$, $(0.9,0.2)$ all evolve into $(1,1)$, which is consistent with the results in Figure 2. When $\beta_{1}=0.4$, all six initial states evolve into $(0,0)$. This is because when the synergy revenue of enterprises cannot reach the basic standard as $\beta_{1}=0.6$, one of the two participants in the game cannot reach the expected total revenues of knowledge sharing and the willingness of knowledge sharing will decrease; as a result, the cooperation state of knowledge sharing will break down. When $\beta_{1}=0.8$, all initial states evolve into $(1,1)$. This is because when the synergy revenue of the enterprise is higher than the basic standard, 
the confidence of enterprises' sharing behavior will be increased, which plays a positive role in the dynamic evolution in the whole network system.

The synergy revenue of knowledge sharing reflects the degree of knowledge complementarity and trust between enterprises. When the synergy revenue of knowledge sharing is higher, enterprises will generate more knowledge and new revenue through cooperative behavior, which will be beneficial to improve the enthusiasm of knowledge sharing behavior of the whole network enterprises over time.

The observation of $\beta_{2}$ shows the same trajectories as $\beta_{1}$ thus will not be otherwise stated.

\subsection{Impact of Risk Coefficient $r_{1}$}

Assume risk coefficient $r_{1}$ takes $0.1,0.25$, and 0.5 , respectively, and keep other variables unchanged to observe the dynamic evolution process as Figure 4.



Figure 4. The dynamic evolution of knowledge sharing strategies with $r_{1}=0.1,0.25,0.5$.

Figure 4 shows that knowledge sharing risk coefficient $r_{1}$ is negatively correlated with network evolution over time. When $r_{1}=0.1$, all the six initial states evolve into $(1,1)$. When $r_{1}=0.25$, the evolution results of the six initial states remain unchanged as shown in Figure 2. When $r_{1}=0.5$, the network results all evolve to $(0,0)$.

The knowledge sharing risk coefficient $r_{1}$ reflects the risk of core knowledge leakage in the process of knowledge sharing. The risk coefficient is closely related to the knowledge correlation between enterprises, the degree of knowledge complementarity, and the knowledge reasoning ability of competitors. Only when the risk of knowledge sharing decreases, the core competitiveness of enterprises will not be influenced, and the motivation of enterprises to adopt knowledge sharing strategy will increase.

\subsection{Impact of Synergy Revenue Distribution Coefficient $\theta$}

Assume synergy revenue distribution coefficient $\theta$ takes $0.3,0.5$, and 0.8 , respectively, and keep other parameters unchanged to observe the dynamic evolution process of the system as Figure 5.

In Figure 5, when $\theta=0.5$, the evolution results remain unchanged as Figure 2. When $\theta=0.3$ or 0.8 , all the six initial states evolve into $(0,0)$. It can be concluded that the synergy revenue distribution coefficient is in a U-shape relationship with the equilibrium of network evolution over time.

The size of the synergy revenue distribution coefficient $\theta$ reflects the proportionality and fairness of collaborative revenue distribution. When the revenue distribution is not fair, the enthusiasm of enterprises adopting knowledge sharing strategy will be deterred; as a result, all enterprises in the network will adopt knowledge-non-sharing strategy over time. 


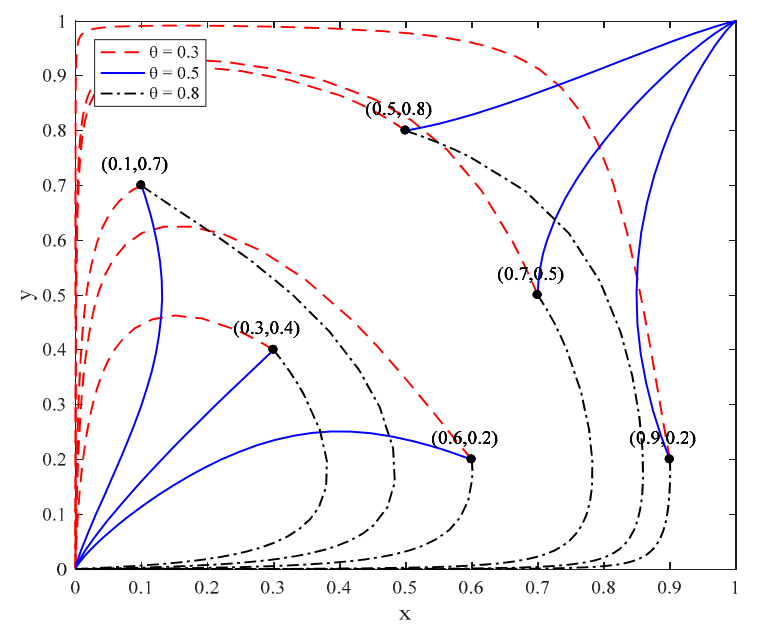

Figure 5. The dynamic evolution of knowledge sharing strategies with $\theta_{1}=0.3,0.5,0.8$.

\subsection{Impact of Opportunity Benefit Coefficient $\eta_{1}$}

Assume the initial state is $(x, y)=(0.4,0.6)$ and the opportunity benefit coefficient $\eta_{1}=0.05,0.1,0.2,0.3,0.6$. The dynamic evolution of the network system over time is observed as Figures 6 and 7 .



Figure 6. The dynamic evolution of Enterprise 1's strategies with $\eta_{1}=0.05,0.1,0.2,0.3,0.6$.

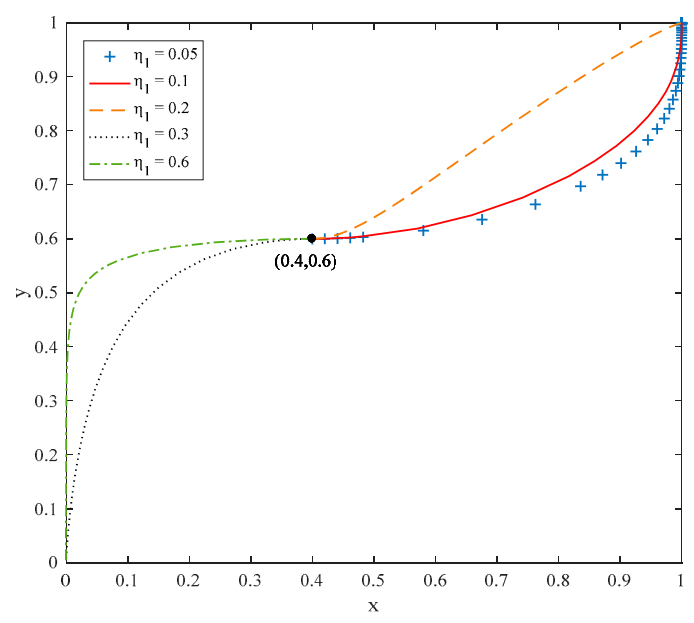

Figure 7. The dynamic evolution of knowledge sharing strategies with $\eta_{1}=0.05,0.1,0.2,0.3,0.6$. 
Taking Enterprise 1 as an example, Figure 6 discusses the influence of opportunity benefit $\eta_{1}$ on strategy selection of Enterprise 1. It can be seen from this figure that with the increase of opportunity benefit $\eta_{1}$, the probability of an enterprise adopting the "quitting midway" knowledge-non-sharing strategy becomes greater.

Figure 7 further verifies that the opportunity benefit $\eta_{1}$ is negatively correlated with the network evolutionary equilibrium over time. When $\eta_{1}=0.05,0.1$ or 0.2 , the network will eventually evolve into $(1,1)$. When $\eta_{1}=0.3$ or 0.6 , the network will eventually evolve into $(0,0)$.

Opportunity benefit $\eta_{1}$ reflects a kind of hitchhiking and moral hazard behavior, which happens when one participant selects the knowledge sharing strategy, while the other intentionally conceals the information and refuses to share its own knowledge but obtains the others' knowledge. This kind of opportunistic behavior is harmful to the development of the whole network. Therefore, reducing the opportunity benefit helps to avoid the opportunist behavior of the participants.

\subsection{Impact of Penalty Cost $\rho$}

Assume the initial state $(x, y)=(0.3,0.4)$ and $\rho=2,5,7,9,11$. The dynamic evolution of the network system over time is observed as Figures 8 and 9 .



Figure 8. The dynamic evolution of Enterprise 1's strategies with $\rho=2,5,7,9,11$.



Figure 9. The dynamic evolution of knowledge sharing strategies with $\rho=2,5,7,9,11$.

Figures 8 and 9 show that the penalty cost $\rho$ is positively correlated with the network evolutionary equilibrium. Taking Enterprise 1 as an example, Figure 8 discusses the influence of penalty cost $\rho$ on 
the strategy selection of enterprise 1 . As can be seen from this figure, with the increase of penalty cost $\rho$, the probability of enterprises choosing the knowledge sharing strategy increases.

Figure 9 continues to verify this conclusion. When $\rho=9,11$, the network will eventually evolve into $(1,1)$, that is, all members in the network adopt the knowledge-sharing strategy. When $\rho=2,5,7$, the network will eventually evolve into $(0,0)$, that is, all members in the network adopt knowledge-non-sharing strategy.

When the penalty cost $\rho$ is too high, enterprises will face serious economic and reputational losses if they adopt the knowledge-non-sharing strategy. Therefore, in order to avoid the opportunistic behavior of enterprises, the third party punishment mechanism should be introduced to promote the positive circle of enterprise knowledge sharing behavior in the cluster innovation network.

\subsection{Impact of Incentive Coefficient $\lambda$}

Assume the initial state $(x, y)=(0.4,0.6), \lambda=0.4,0.6,0.7,0.9$. The dynamic evolution of the network system over time is observed as Figure 10.

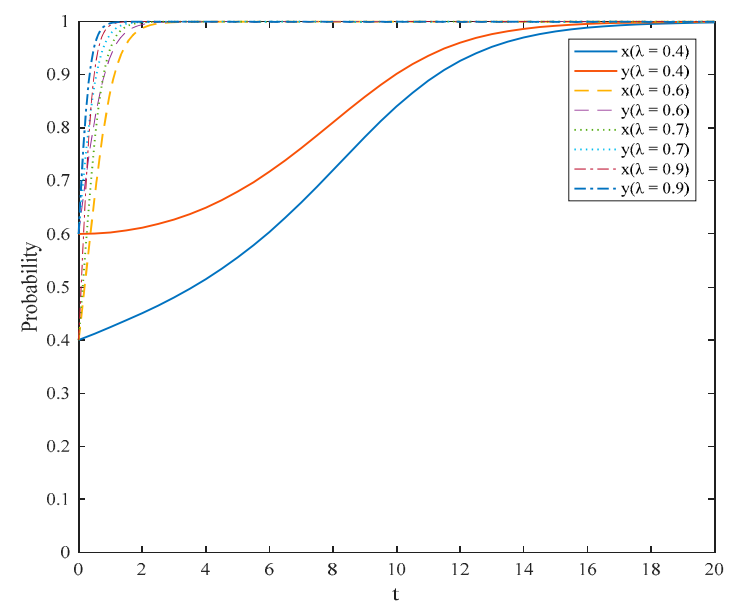

Figure 10. The dynamic evolution of network system over time with $\lambda=0.4,0.6,0.7,0.9$.

As can be seen from Figure 10, the incentive coefficient $\lambda$ is positively correlated with the network evolutionary equilibrium. With the increase of $\lambda$, the network is more likely to converge to $(1,1)$ and the convergence speed is increasingly faster. The incentive coefficient $\lambda$ refers to the third party's encouragement for enterprises adopting knowledge sharing strategy proactively.

The incentive coefficient $\lambda$ is a coefficient for the third party to encourage enterprises to proactively adopt knowledge-sharing strategy. Therefore, an incentive mechanism should be formulated to strengthen the encouragement of enterprise adopting knowledge sharing, which is conducive to improving the enthusiasm of knowledge sharing and promoting the vigorous development of innovation cooperation.

\subsection{Impact of Knowledge Sharing Cost $c_{1}$}

Assume the initial state $(x, y)=(0.4,0.6), c_{1}=5,8,11,14$. The dynamic evolution of the network system over time is observed as Figure 11.

Figure 11 shows that knowledge sharing $\operatorname{cost} c_{1}$ is negatively correlated with the network evolution equilibrium. When $c_{1}=5,8$, the network evolves into $(1,1)$, that is, all members of the network will adopt knowledge sharing strategy over time. When $c_{1}=11,14$, the network evolves into $(0,0)$, that is, all members of the network will adopt knowledge-non-sharing strategy over time. $c_{1}$ represents the costs of knowledge sharing among enterprise members, including opportunity cost, technical cost, material cost, and time cost in the process of knowledge sharing behavior. When the direct cost among network members are too high, the enthusiasm of enterprise adopting knowledge sharing will be 
reduced. Moreover, attention should be paid to the communication costs caused by physical distance and cultural differences in the process of knowledge sharing.

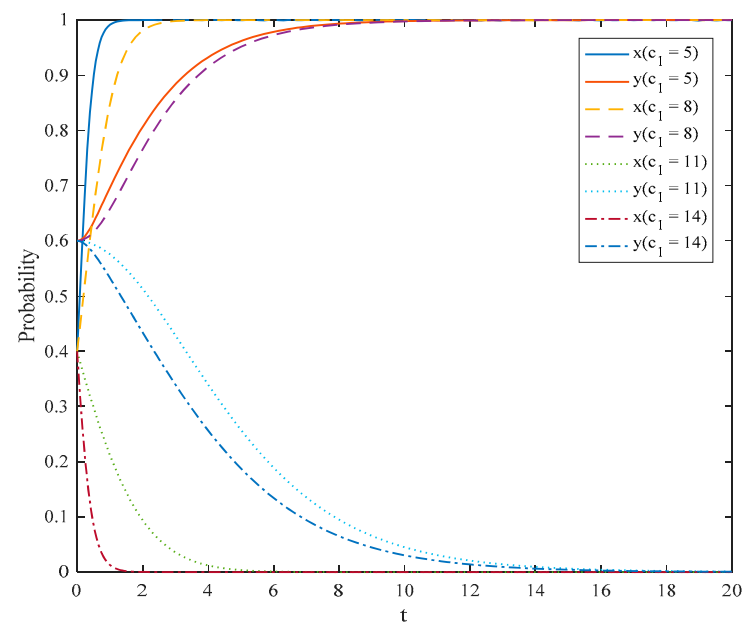

Figure 11. The dynamic evolution of network system over time with $c_{1}=5,8,11,14$.

\subsection{Impact of Direct Revenue Coefficient $\alpha_{1}$}

Assume the initial state $(x, y)=(0.4,0.6), \alpha_{1}=0.3,0.5,0.7,0.9$. The dynamic evolution of the network system over time is observed as Figure 12.

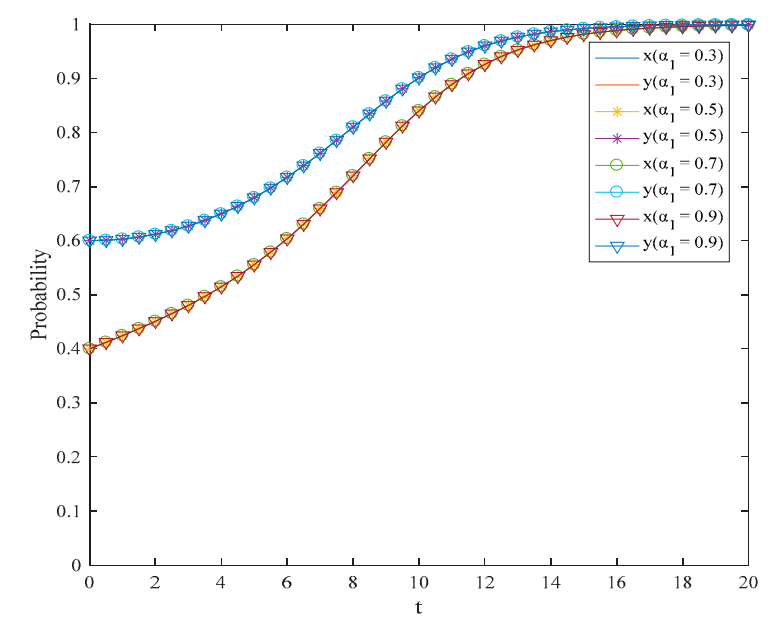

Figure 12. The dynamic evolution of network system over time, with $\alpha_{1}=0.3,0.5,0.7,0.9$.

As can be seen from Figure 12, the direct revenue coefficient $\alpha_{1}$ does not affect the dynamic evolution in cluster innovation network. The direct revenue coefficient $\alpha_{1}$ is the embodiment of one enterprise's ability to absorb knowledge shared by the other, which is closely related to the enterprise's own knowledge stock, autonomous learning ability, etc. In Figure 12, the curves of different $\alpha_{1}$ overlap, that is, the values of $\alpha_{1}$ do not affect the evolutionary trajectory of the network, because the $\alpha_{1}$ is not reflected in the saddle point $E\left(x^{*}, y^{*}\right)$ of the network. Therefore, although the direct revenue of enterprise knowledge sharing behavior is conducive to improving the enthusiasm of knowledge sharing, it has little impact on either the process or final results of the overall network dynamic evolution. 


\section{Conclusions}

\subsection{Discussion}

Proactive knowledge sharing behavior can usher successful knowledge innovation, which includes constantly absorbing existing knowledge and creating new knowledge. Simultaneously, it is also a complicated game process whether enterprises choose knowledge sharing strategy in cluster innovation network over time. Different from the classical game theory in which the perfectly rational person is assumed, evolutionary game theory emphasizes the bounded rationality of subjects, that is, enterprises have the ability of learning, imitation and strategy renewal. By using evolutionary game theory, this paper proposes a new game model of knowledge sharing behavior among enterprises in order to capture the interactive behavior of knowledge sharing and investigate the dynamic evolutionary mechanism in the whole network. This paper systematically discusses the influence factors of knowledge sharing behavior among enterprises, and divides the influence factors into three levels: basic cost-benefit factors, fair distribution mechanism factors, and external incentive and penalty factors. The evolutionary game model of knowledge sharing in cluster enterprises is established by using game payoff matrix. After that, the network evolutionary trajectory of knowledge sharing behavior is deduced by using replicator dynamics equation theory. Finally, the impact of each variable is simulated by using Matlab. The following results are obtained:

1. The evolutionary model of enterprises' knowledge sharing behavior in cluster innovation network has an evolutionary equilibrium solution over time. The results of network evolution only exist in two cases: all enterprises choose knowledge sharing strategy or not.

2. The dynamic evolution equilibrium of enterprise knowledge sharing is related to the initial states of the system.

3. The factors of the knowledge sharing synergy revenue, the knowledge sharing incentive revenue, the penalty cost and incentive revenue positively affect the evolution results of the network. With the increase of these factors, all the enterprises in the network finally adopt knowledge sharing strategy.

4. The factors of the knowledge sharing risk, the knowledge sharing cost and the opportunity benefit negatively affect the evolution of the network. With the increase of these factors, all the enterprises in the network finally adopt knowledge-non-sharing strategy.

5. The synergy revenue distribution presents an inverted $U$ shape relationship with the evolution results. Only when the revenues are distributed fairly, the enterprises in the network would choose the knowledge sharing strategy.

6. The direct revenue of knowledge sharing does not affect the results of network evolution.

To sum up, through exploring the long-term evolutionary law of knowledge sharing behavior among bounded rational enterprises in the cluster innovation network and adjusting these influence factors, enterprises can be encouraged to adopt knowledge sharing strategies. Over time, the whole network will form a virtuous cycle of knowledge sharing, which will be conducive to the sustainable knowledge innovation of enterprises, thus promote the maintenance of core competitiveness and the improvement of sustainable innovation of enterprises.

\subsection{Management Implications}

According to the results of this paper, the following implications can be obtained for the network managers to stimulate enterprises to adopt knowledge sharing proactively. The implications are sorted out as: individual attributes, knowledge characteristics, and situational factors.

1. From the perspective of individual attributes, more attention should be paid to the management of inter-enterprise relationships to motivate enterprises to adopt knowledge sharing strategy with enthusiasm. The mutual trust between enterprises should be constantly strengthened, 
especially so when at the early stage of cooperation, which will create a good environment for raising the knowledge sharing enthusiasm and collaborative willingness. Moreover, targeting at different knowledge demands, a complete staff training system should be developed to enhance the enterprises' knowledge sharing ability.

2. From the perspective of knowledge characteristics, to facilitate the communication of knowledge, three suggestions are put forward as follows: Firstly, following the tide of global information can improve the convenience and accuracy of knowledge sharing within the network. Efficient information transmission would reduce information asymmetry among enterprises. Secondly, enterprises should be fitted with reasonable knowledge structure and elaborated labor division. Lastly, it is also vital that all the network members should pay attention to protect their core knowledge from leakage.

3. From the perspective of situational factors, external supervision mechanism should be established by network managers. Reasonable incentive and penalty mechanisms play a significant role in promoting knowledge sharing behavior. To discourage the immoral behavior, signing contracts is a good protection for enterprises to carry out knowledge sharing strategy; meanwhile, penalty for immoral behavior is also a good backup force to deter the contract breach and free-riding behavior. Moreover, the reputation system should be established. If an enterprise chooses adverse behavior, its image and reputation would be downgraded; in contrast, if an enterprise chooses knowledge sharing strategy proactively, the promotion of reputation would bring more cooperation opportunities. Lastly, it is a good practice for the government to modify the intellectual property protection mechanism and optimize market credit environment.

The cluster innovation network will be optimized and the willingness of enterprises to share knowledge will be enhanced if the above implications can be effectively implemented. Over time, the cluster innovation network will become a benign and ecological system for continuous knowledge sharing and win-win cooperation, which will promote sustainable knowledge innovation, thus providing inexhaustible impetus for the sustainable development of enterprises.

\subsection{Limitations and Future Research}

Despite the promising outcomes of knowledge sharing presented by this paper, there are still limitations which can be addressed in future research. Firstly, we assume that the cluster innovation network is a uniformly mixed network, and the replication dynamics equation is used to solve the evolutionary results. However, the real enterprise network usually has complex network structure attributes such as scale-free and small world. Hence, the method of replication dynamics equation may not meet the demands of evolutionary problem under the complex heterogeneous network. Secondly, empirical data is also needed to verify the results obtained by this paper.

In response to the limitations, future research would consider the impact of complex network topology on the knowledge sharing behavior among enterprises in the cluster network. The research of "evolutionary game of complex network" would be referred to. In addition, more empirical experiments are needed to verify and support this research.

Author Contributions: Conceptualization, X.K.; methodology, X.K.; software, X.K.; visualization, X.K.; formal analysis, X.K.; investigation, X.K.; resources, X.K.; data curation, X.K. and T.Z.; writing-original draft preparation, X.K.; writing - review and editing, X.K. and T.Z.; visualization, X.K.; supervision, Q.X.; project administration, Q.X.; funding acquisition, Q.X. All authors have read and agreed to the published version of the manuscript.

Funding: This research was funded by the National Natural Science Foundation of China (Grant No. 71572033,71832001) and the Fundamental Research Funds for the Central Universities (Grant No. CUSF-DH-D-2019100).

Acknowledgments: The authors gratefully acknowledge the financial support from the National Natural Science Foundation of China (Grant No. 71572033, 71832001) and the Fundamental Research Funds for the Central Universities (Grant No. CUSF-DH-D-2019100), and would like to thank the anonymous reviewers for their insightful comments. 
Conflicts of Interest: The authors declare no conflicts of interest.

\section{References}

1. Goh, A.L.S. Harnessing knowledge for innovation: An integrated management framework. J. Knowl. Manag. 2005, 9, 6-18. [CrossRef]

2. Law, C.C.H.; Ngai, E.W.T. An empirical study of the effects of knowledge sharing and learning behaviors on firm performance. Expert Syst. Appl. 2007, 34, 2342-2349. [CrossRef]

3. Liu, H.Y.; Zhao, S.K.; Xin, O. Analysis on the Evolution Path and Hotspot of Knowledge Innovation Study Based on Knowledge Map. Sustainability 2019, 11, 5528. [CrossRef]

4. He, W.; Wei, K.K. What drives continued knowledge sharing? An investigation of knowledge-contribution and -seeking beliefs. Decis. Support Syst. 2007, 46, 826-838. [CrossRef]

5. Kong, E. The new knowledge management: Complexity, learning, and sustainable innovation. Long Range Plan. 2003, 36, 411-412. [CrossRef]

6. Esteve, A.; Ramon, C.M. Open versus closed innovation: A model of discovery and divergence. Acad. Manag. Rev. 2010, 35, 27-47.

7. West, J.; Salter, A.; Vanhaverbeke, W.; Chesbrough, H. Open innovation: The next decade. Res. Policy 2014, 43, 805-811. [CrossRef]

8. Fang, W.; Xiao, L.M. Simulation of knowledge transfer process model between universities: A perspective of cluster innovation network. Complexity 2018, 2018, 5983531.

9. Nonaka, I.; Kodama, M.; Hirose, A.; Kohlbacher, F. Dynamic fractal organizations for promoting knowledge-based transformation-A new paradigm for organizational theory. Eur. Manag. J. 2014, 32, 137-146. [CrossRef]

10. Han, J. Technology commercialization through sustainable knowledge sharing from University-Industry collaborations, with a focus on patent propensity. Sustainability 2017, 9, 1808. [CrossRef]

11. King, J.M. The Airbus 380 and Boeing 787: A role in the recovery of the airline transport market. J. Air Transp. Manag. 2007, 13, 16-22. [CrossRef]

12. Kim, M.; Song, J.; Triche, J. Toward an integrated framework for innovation in service: A resource-based view and dynamic capabilities approach. Inf. Syst. Front. 2015, 17, 533-546. [CrossRef]

13. Hayter, C.S. Constraining entrepreneurial development: A knowledge-based view of social networks among academic entrepreneurs. Res. Policy 2016, 45, 475-490. [CrossRef]

14. Luo, S.; Du, Y.; Liu, P.; Xuan, Z.; Wang, Y. A study on coevolutionary dynamics of knowledge diffusion and social network structure. Expert Syst. Appl. 2015, 42, 3619-3633. [CrossRef]

15. Zhang, J.M.; Jiang, H.; Wu, R.; Li, J.Z. Reconciling the dilemma of knowledge sharing: A network pluralism framework of firms' R\&D alliance network and innovation performance. J. Manag. 2019, 45, 2635-2665.

16. Trkman, P.; Desouza, K.C. Knowledge risks in organizational networks: An exploratory framework. J. Strateg. Inf. Syst. 2012, 21, 1-17. [CrossRef]

17. Li, Q.; Kang, Y. Knowledge sharing willingness and leakage risk: An evolutional game model. Sustainability 2019, 11, 596. [CrossRef]

18. Maria, M.D.; Francesca, G.; Vincenzo, S. Free-riding and knowledge spillovers in teams: The role of social ties. Eur. Econ. Rev. 2019, 112, 74-90.

19. Frishammar, J.; Ericsson, K.; Patel, P.C. The dark side of knowledge transfer: Exploring knowledge leakage in joint R\&D projects. Technovation 2015, 41, 75-88.

20. Klarl, T. Knowledge diffusion and knowledge transfer revisited: Two sides of the medal. J. Evol. Econ. 2014, 24, 737-760. [CrossRef]

21. Aumann, R.J. Rationality and bounded rationality. Games Econ. Behav. 2004, 21, 2-14. [CrossRef]

22. Frey, E. Evolutionary game theory: Theoretical concepts and applications to microbial communities. Phys. A Stat. Mech. Appl. 2010, 389, 4265-4298. [CrossRef]

23. Harrisson, D.; Laberge, M. Innovation, identities and resistance: The social construction of an innovation network. J. Manag. Stud. 2002, 39, 497-521. [CrossRef]

24. Debresson, C.; Amesse, F. Networks of innovators: A review and introduction to the issue. Res. Policy 1991, 20, 363-379. [CrossRef] 
25. Purchase, S.; Olaru, D.; Denize, S. Innovation network trajectories and changes in resource bundles. Ind. Mark. Manag. 2014, 43, 448-459. [CrossRef]

26. Barney, J. Firm resources and sustained competitive advantage. J. Manag. 1991, 17, 99-120. [CrossRef]

27. Grant, R.M. Toward a knowledge-based theory of the firm. Strateg. Manag. J. 1996, 17, 109-122. [CrossRef]

28. Ketokivi, M.; Mahoney, J.T. Asymptotic theory of transaction costs. Acad. Manag. Learn. Educ. 2016, 15, 123-138. [CrossRef]

29. Inkpen, A.C.; Tsang, E.W.K. Social capital, networks, and knowledge transfer. Acad. Manag. Rev. 2005, 30, 146-165. [CrossRef]

30. Greenwood, M.; Vanburen, H.J. Trust and Stakeholder Theory: Trustworthiness in the Organisation-Stakeholder Relationship. J. Bus. Ethics 2010, 95, 425-438. [CrossRef]

31. Butler, J.K., Jr. Trust expectations, information sharing, climate of trust, and negotiation effectiveness and efficiency. Group Organ. Manag. 1999, 24, 217-238. [CrossRef]

32. Kong, D.T.; Dirks, K.T.; Ferrin, D.L. Interpersonal trust within negotiations: Meta-analytic evidence, critical contingencies, and directions for future research. Acad. Manag. J. 2014, 57, 1235-1255. [CrossRef]

33. Nooshinfard, F.; Nemati-Anaraki, L. Success factors of inter-organizational knowledge sharing: A proposed framework. Electron. Libr. 2014, 32, 239-261. [CrossRef]

34. Hashim, K.F.; Tan, F.B. The mediating role of trust and commitment on members' continuous knowledge sharing intention: A commitment-trust theory perspective. Int. J. Inf. Manag. 2015, 35, 145-151. [CrossRef]

35. Cheng, J.H.; Yeh, C.H.; Tu, C.W. Trust and knowledge sharing in green supply chains. Supply Chain Manag. 2008, 13, 283-295. [CrossRef]

36. Zhang, P.; Ng, F.F. Explaining knowledge-sharing intention in construction teams in Hong Kong. J. Constr. Eng. Manag. 2013, 139, 280-293. [CrossRef]

37. Chen, S.H. The Influencing factors of enterprise sustainable innovation: An empirical study. Sustainability 2016, 8, 425. [CrossRef]

38. Ahn, S.Y.; Kim, S.H. What makes firms innovative? The role of social capital in corporate innovation. Sustainability 2017, 9, 1564. [CrossRef]

39. Samaddar, S.; Kadiyala, S.S. An analysis of interorganizational resource sharing decisions in collaborative knowledge creation. Eur. J. Oper. Res. 2006, 170, 192-210. [CrossRef]

40. Lin, L.N.; Wang, H. Dynamic incentive model of knowledge sharing in construction project team based on differential game. J. Oper. Res. Soc. 2019, 70, 2084-2096. [CrossRef]

41. Jiang, Z.S.; Hao, Y.H. Game analysis of technology innovation alliance stability based on knowledge transfer. Comput. Math. Organ. Theory 2013, 19, 403-421. [CrossRef]

42. Wang, X.G. Forming mechanisms and structures of a knowledge transfer network: Theoretical and simulation research. J. Knowl. Manag. 2013, 17, 278-289. [CrossRef]

43. Li, J.J.; Zhang, Y.M.; Man, J.Y.; Zhou, Y.; Wu, X.J. SISL and SIRL: Two knowledge dissemination models with leader nodes on cooperative learning networks. Phys. A Stat. Mech. Appl. 2017, 468, 740-749. [CrossRef]

44. Wang, H.Y.; Wang, J.; Ding, L.T.; Wei, W. Knowledge transmission model with consideration of self-learning mechanism in complex networks. Appl. Math. Comput. 2017, 304, 83-92. [CrossRef]

45. Zhu, H.; Ma, J. Knowledge diffusion in complex networks by considering time-varying information channels. Phys. A Stat. Mech. Appl. 2018, 494, 225-235. [CrossRef]

46. Cao, B.; Han, S.H.; Jin, Z. Modeling of knowledge transmission by considering the level of forgetfulness in complex networks. Phys. A Stat. Mech. Appl. 2016, 451, 277-287. [CrossRef]

47. Ho, S.; Hsu, Y.; Lin, E. Model for knowledge-sharing strategies: A game theory analysis. Eng. Proj. Organ. J. 2011, 1, 53-65. [CrossRef]

48. Evans, S.N.; Hening, A.; Schreiber, S.J. Protected polymorphisms and evolutionary stability of patch-selection strategies in stochastic environments. J. Math. Biol. 2015, 71, 325-359. [CrossRef]

49. Stahn, H. A remark on rational expectation equilibria with incomplete markets and real assets. J. Math. Econ. 2000, 33, 441-448. [CrossRef]

50. Jiang, G.Y.; Ma, F.C.; Shang, J.; Chau, P.Y.K. Evolution of knowledge sharing behavior in social commerce: An agent-based computational approach. Inf. Sci. 2014, 278, 250-266. [CrossRef]

51. Chen, S.H. An Evolutionary game model of knowledge workers' counterproductive work behaviors based on preferences. Complexity 2017, 2017, 3295436. [CrossRef] 
52. Liu, L.; Chen, G.; Niu, X. Game analysis of the knowledge sharing mechanism for the supply chain collaborative innovation. J. Ind. Eng. Manag. 2015, 8, 152-169. [CrossRef]

53. Erkal, N.; Minehart, D. Optimal technology sharing strategies in dynamic games of R\&D. J. Econ. Manag. Strategy 2014, 23, 149-177.

54. Cressman, R.; Tao, Y. The replicator equation and other game dynamics. Proc. Natl. Acad. Sci. USA 2014, 111, 10810-10817. [CrossRef] [PubMed] 